\title{
Exploring customer engagement behavior: construct proposal and its antecedents
}

\author{
Completed Research Paper
}

\author{
Jaime Romero ${ }^{1}$ \\ Universidad Autónoma de Madrid \\ jaime.romero@uam.es
}

\author{
Shintaro Okazaki \\ King's College London \\ shintaro.okazaki@kcl.ac.uk
}

\begin{abstract}
Customer engagement behavior (CEB) receives increasing attention from both academics and practitioners, as it represents one of the key customer profitability determinants. This study attempts to provide a holistic view of CEB by (1) proposing an instrument to measure CEB, and (2) its antecedents. Based on the existent literature, we conceptualize CEB as a formative construct consisting of word-of-mouth (WOM), loyalty program participation, customer interaction, and co-creation, which are determined by relationship quality, rewards, selfenhancement, learning, social integration, and company identification. In attempt to test these propositions, an online survey is conducted with 466 respondents. Our results provide empirical support for our proposed CEB construct, while corroborating five out of the six hypothesized antecedents. In closing, theoretical as well as managerial implications are discussed, while important limitations are recognized and future research directions are proposed.
\end{abstract}

Keywords: Co-creation, Customer engagement behavior, Customer interaction, Loyalty program, Word-of-mouth

\section{Introduction}

Customer engagement receives increasing attention from marketing academics and practitioners. When customers are engaged, they can contribute to company results through mechanisms other than transactions (i.e., purchases). Focusing on acquisition, retention, and share-of-wallet is no longer enough. Consequently, customer engagement can lead to business opportunities and ensuring profitability (Verhoef et al., 2010). Customer engagement research has adopted two different perspectives. On one hand, customer engagement can be examined from a psychological perspective. Here, customer engagement is defined as a psychological state that occurs because of customer interaction with a focal object, such as brand, in service relationships (Brodie et al., 2011). On the other hand, customer engagement can be examined from a behavioral point of view. In this approach, research is focused more on customer engagement behavior (CEB) than on customer engagement (e.g., Kumar et al., 2010). CEB can be defined as "customer's behavioral manifestations that have a brand or firm focus, beyond purchase, resulting from motivational drivers" (Van Doorn et al., 2010).

In both perspectives, there is a call for further research about the composition as well as the antecedents of CEB (Brodie et al., 2011; van Doorn, 2010). To date, our knowledge of these antecedents typically comes from research about the antecedents of some specific behaviors usually associated with customer engagement, such as word-of-mouth (WOM) or co-creation (e.g., Hennig-Thurau et al., 2004; Bettencourt, 1997). Yet, we still lack an integrative perspective of the antecedents of customer engagement that provides us with a deep

\footnotetext{
${ }^{1}$ Acknowledgements: Project ECO2012-31517 (Ministerio de Economía y Competitividad)
} 
understanding of the phenomenon; consequently, it is not possible to reach adequate insights for managers. They need a broader and more holistic view of their customers instead of a fragmented perspective that arises when analyzing customers separately through several media and channels. Organizations, especially in B2C markets, are interested in understanding how emotional ties, social influences, service experiences, etc. interact to create customer engagement (Bolton, 2011), which is something that we still ignore (Van Doorn et al. 2010). Adopting a behavioral perspective of customer engagement, this study develops a theoretical model that jointly analyses the antecedents of CEB. In particular, we concentrate our efforts on antecedents that might simultaneously influence CEB. We explicitly omit antecedents that according to previous research only influence a CEB. The remainder of this manuscript is organized as follows: In the next section, we provide the theoretical background of this study, and then we present our research design and its main results. Finally, we discuss our findings and its main implications.

\section{Literature Review and Research Hypotheses}

\subsection{Customer engagement behavior (CEB)}

Along with customer purchases, CEB generates value for companies. From a marketing perspective, CEB must be examined in terms of how they can grow or reduce value for the company. In this regard, CEB grows or diminishes firm value through three mechanisms, apart from product purchases: by recommending the brand in exchange of some incentives, by influencing other customers via WOM or through other types of information sharing, and by providing feedback that can be useful for product development or improvement (Kumar et al., 2010). On this basis, we propose CEB as a composite of loyalty program participation, WOM, customer interaction, and co-creation.

Loyalty program incentivizes current customers' recommendations with coupons, free samples, gifts, etc. aiming to incentivize continued patronage and repeated purchase (Ruy and Feick 2007). Loyalty program can reduce acquisition costs and generate future cash flows to companies (Dowling and Uncles, 1997). In contrast, WOM is a non-incentivized behavior in which a consumer informally communicates an experience, evaluation, or recommendation in relation to goods or services to another consumer (Anderson, 1998). Customers can receive information from many personal sources, but its credibility would depend on the type of interpersonal relationships (Godes and Mayzlin, 2004). WOM involves an exchange of marketing information between consumers and plays a key role in modifying consumer attitudes and behaviors regarding products and services (Chu and Kim, 2011), which affects not only acquisition but also retention and share-of-wallet (Kumar et al., 2010). With the spread of information technologies, WOM also takes place in virtual environments, such as customer blogs, emails, websites, online forums, communities, and social networks (Chu and Kim, 2011). Here, the statements made by a customer or prospect customers about a product or a brand are available over the Internet to a large number of people and institutions.

Consumers not only can provide value for the company through their recommendations (incentivized or not), but also can contribute to profitability through customer interaction (van Doorn et al., 2010, Kumar et al., 2010). Customer interaction arises from interactions between the customer and other customers and between the customer and the firm (Grönroos, 2012). In this study, we consider customer interaction to be related to customers' suggestions that facilitate other customers' decision making and enhance their experience with the firm (e.g., van Doorn et al., 2010). On the other hand, co-creation refers to interactions between the customer and the firm that lead to the improvement of current services or the development of new ones. With customer interaction, customers positively impact other customers' attitudes, 
hence indirectly providing value for the company. In contrast, by co-creation, customers provide value for the firm directly.

\subsection{Antecedents of $C E B$}

As illustrated in Figure 1 we posit that CEB can be driven by six antecedents: relationship quality, rewards, self-enhancement, learning, social integration, and company identification. Some of these antecedents are the result of past customer interaction with products and brands (or in general with companies) or with other customers, while others are expected outcomes of future interactions.

Relationship marketing has extensively studied the outcome of the interactions between companies and customers. The relationship quality summarizes these interactions across time for a customer. Hennig-Thurau and Klee (1997) define relationship quality as the degree to which a relationship is appropriate to meet the consumer needs associated with that relationship. The relationship quality captures the nature of the relationship (Macintosh, 2007). Unlike service quality, this construct takes into account the overall relationship and not only the quality of specific service interactions (Shabbir et al., 2007). The relationship quality has three main components: satisfaction, trust, and commitment (Hennig-Thurau et al., 2002). Several studies have demonstrated that WOM is positively influenced by the relationship quality or some of its components, i.e., commitment, satisfaction, or trust (e.g., Brown et al., 2005; Macintosh, 2007; Hennig-Thurau et al., 2002; Ng, David, and Dagger, 2011).

Relationship quality could also affect customer interaction. Nambisan and Baron (2007) show that positive attitudes toward the firm would stimulate interactions among online users. This happens because customers are aware that sharing information with peer customers somehow benefits the company; therefore, with positive attitudes toward the firm, they are more inclined to benefit the firm indirectly by sharing their knowledge with other customers. The relationship quality summarizes the main attitudes of the customer toward the firm. Therefore, we can also expect that relationship quality can have a positive impact on CEB.

Relationship quality might also influence CEB, given that commitment and satisfaction also appear to impact co-creation. Commitment involves the psychological attachment of consumers who believe in the importance of maintaining their relationship with the company (Morgan and Hunt, 1994). Thus, commitment leads consumers to sacrifice themselves for the welfare of the company, to take care of it, and to perform certain actions that do not depend solely on rewards and punishments. Bettencourt (1997) demonstrates that committed consumers feel involved in the development of the company, which leads to co-creation; they tend to play the role of company consultants. However, he also finds that satisfaction is negatively related to co-creation. The latter could happen because consumers might express ideas that improve service quality only when dissatisfaction arises. In his research, the effect of commitment is slightly higher than the effect of satisfaction and therefore, although low, we expect that the influence of relationship quality on co-creation to be positive.

Rewards are an adequate tool for encouraging recommendations (Wirtz et al., 2012). Particularly, rewards are more effective in the case of weak brands than for strong brands. Customers of strong brands usually do not need huge incentives to participate in loyalty programs. In contrast, customers have to be rewarded more heavily in the case of weaker brands because customers are less confident about recommending the brand and are therefore less motivated to perform such an action (Ryu and Feick, 2007).

H1: Relationship quality directly and positively affects CEB.

H2: Rewards directly and positively affect CEB.

Besides relationship quality and rewards, CEB can also arise from other motivations, particularly the benefits that customers anticipate from such behaviors - the consequences of 
CEB can also act as antecedents of these behaviors (Brodie et al. 2011). These benefits are personal and social (Hennig-Thurau et al., 2004; Nambisan and Baron, 2010). The most relevant personal benefits that might influence several CEB are self-enhancement and learning about the product. Self-enhancement is the positive recognition that a customer obtains from others by projecting themselves as intelligent shoppers (Sundaram et al., 1998) or service users. Self-enhancement positively affects WOM (Sundaram et al., 1998; HenningThurau et al., 2004). Besides, it also encourages customer interaction. When sharing their experiences or knowledge about the product, customers have the opportunity to grow their prestige and status. This increases customer participation in customer interaction (Wasko and Faraj, 2005). Thus, the higher a customer's expectations of heightening her or his image the more customer interaction will take place. Co-creation activities can help customers fulfill their self-esteem needs (Oyedele and Simpson, 2013) and can be used as a signal of expertise if the contributions of the consumer to the company are somehow visible to others, e.g., in virtual communities (Franke and Sha, 2003). Therefore, self-enhancement can be also positively associated with performing co-creation behaviors.

H3: Self-enhancement directly and positively affects CEB.

Learning about the product is another important benefit that customers obtain from their interactions with other customers (Wasko and Faraj, 2000), and it involves acquiring a better understanding and knowledge about company services and their usage. Through these interactions with other customers, they acquire knowledge that can enhance product usage, particularly for technology-based products. Online environments particularly facilitate learning from other customers (Libai et al., 2010) or, in the case of online communities, from other members (Franke and Sha, 2003). Customers expecting to achieve learning benefits from their interactions with other peers should be prone to perform such behaviors (Nambisan and Baron, 2007, 2010). In addition, customers can also expect to learn from their interactions with companies in co-creation behaviors. Sometimes their suggestions and ideas for product improvement elicit some responses from companies that have a high informational value, such as future developments of the product. Such expected learning might therefore lead customers to co-creation (Nambisan and Baron, 2010).

H4: Learning directly and positively affects CEB.

Social integration includes the feeling that one is a member of a community. This usually provides a chance to interact with other members. This social benefit might be positively related with CEB. For instance, in web-based opinion platforms, WOM allows customers to become part of online communities. The expected interactions with other customers derived from WOM are a reason to perform this CEB (Henning-Thurau et al., 2004). Individuals who value social integration usually enjoy interacting with others, which facilitates knowledge sharing (Xu et al., 2012). Through these interactions, customers set affective relationships that encourage commitment or responsibility toward other individuals (Wasko and Faraj, 2005, Nambisan and Baron, 2010), thus enhancing information sharing. Therefore, the more important a customer considers social integration the higher customer interaction should be. Similarly, customers who value social integration should also enjoy interacting with companies. Therefore, we can also expect that social integration is positively associated with co-creation too.

H5: Social integration directly and positively affects CEB.

Finally, another important antecedent of CEB is company identification, which can be defined as the cognitive connection that a customer makes between her/his own definition and the definition of the company (Dutton et al., 1994). As with relationship quality, this antecedent is not a benefit that customers expect to obtain from specific interactions with the company or with other customers. Company identification might be associated with CEB. Consumers who share common values with a firm have a greater desire to maintain a 
connection with it (Morgan and Hunt, 1994) and perform behaviors that are favorable for the company (Bergami and Bagozzi, 2000).

First, company identification favors WOM (Bhattacharya and Sen, 2003). This could happen because consumers say positive things about the company as a means to express their own identity; therefore, the greater the company identification the greater the likelihood is that the individual transmits positive messages about the company (Brown et al., 2005). Secondly, we expect that company identification enhance co-creation, particularly by moderating the impact of self-enhancement and learning (Nambisan and Baron, 2010). Company identification helps customers to build their own identities (Bhattacharya and Sen, 2003), as self-enhancement; therefore, the value that customers obtain from the recognition of other customers due to their contributions to the company might be higher if there is a strong company identification.

H6: Company identification directly and positively affects CEB.

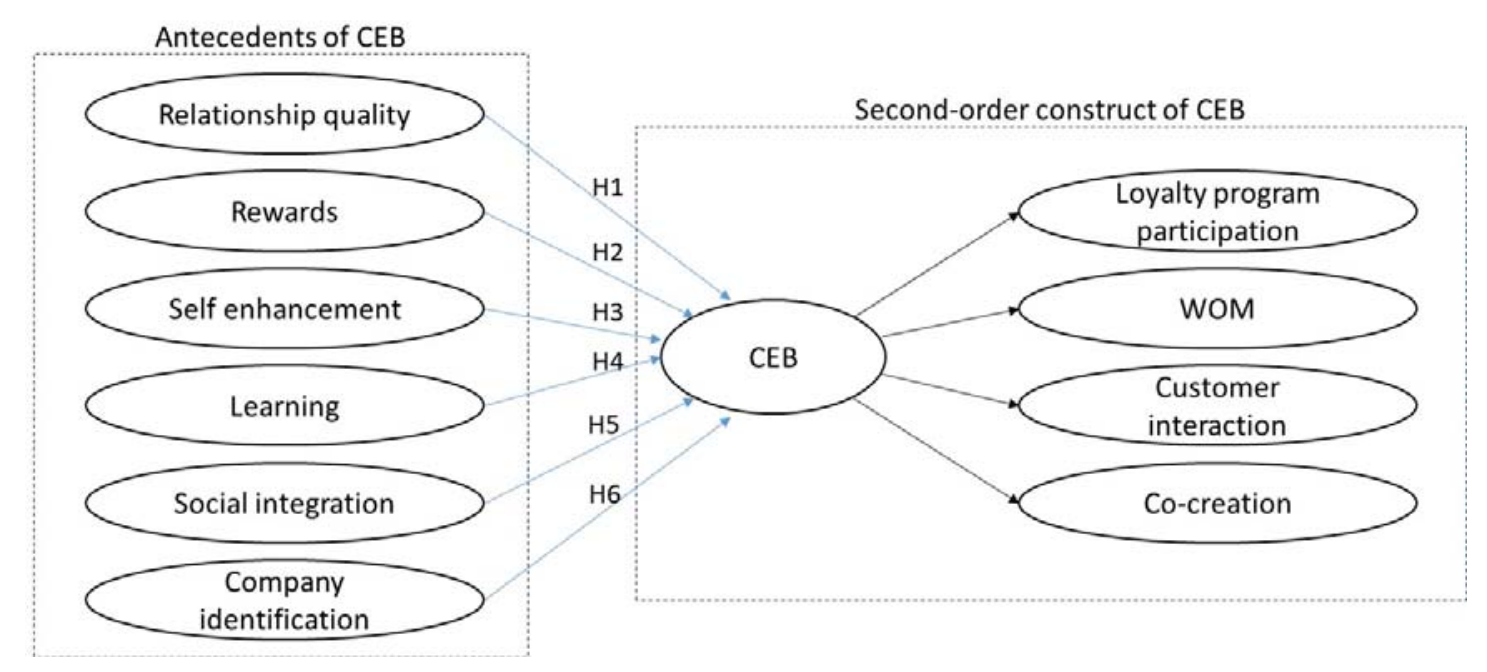

Figure 1: Research model

\section{Methodology}

\subsection{Sample and procedure}

For the purpose of this research, we conducted a survey among customers of online travel agencies. These types of agencies provide their services in a virtual environment, which usually facilitates the CEB we considered in this study: WOM, loyalty program participation, customer interactions, and co-creation (e.g., Kim et al., 2013). We focused on specific online agencies in order to ensure the existence of loyalty programs and of platforms that facilitate customers' interactions. In particular, our respondents were customers of one of these two travel agencies: Atrápalo or Logitravel. These companies reward customers through loyalty programs, mainly implemented in social networks, such as Facebook. Our two online travel agencies have also set mechanisms that facilitate customer interactions. They all offer their customers the chance to share their experiences about services that have been booked or purchased through their websites. For instance, in the case of hotels, customers can rate them in terms of several criteria (room cleanliness, location, meals, etc.) and comment on their advantages and drawbacks. These evaluations are taken into account by other customers when making their purchase decisions. Note that these opinions are not focused on the services provided by the company and therefore do not constitute WOM about the travel agencies. 
Table 1. Measurement Items

\begin{tabular}{|c|c|}
\hline Items & M \\
\hline \multicolumn{2}{|l|}{ WOM $(\alpha=0.95 ; \mathrm{CR}=0.96 ; \mathrm{AVE}=0.82 ;$ Brown et al. 2005$)$} \\
\hline I mention to others that I do business with this OTA (online travel agency). & $4.62(1.46)$ \\
\hline I make sure that others know that I do business with this OTA. & $4.20(1.54)$ \\
\hline I recommended this OTA to family members. & $4.84(1.36)$ \\
\hline I speak positively of this OTA to others. & $4.90(1.36)$ \\
\hline I recommend this OTA to acquaintances. & $4.92(1.39)$ \\
\hline I recommended this OTA to close personal friends. & $5.02(1.39)$ \\
\hline \multicolumn{2}{|l|}{ Loyalty program participation $(\alpha=0.93 ; \mathrm{CR}=0.95 ; \mathrm{AVE}=0.83$ ) } \\
\hline I participate in the draws that this OTA organizes at social networks. & $3.56(1.64)$ \\
\hline I participate in the contests that this OTA organizes at social networks. & $3.55(1.66)$ \\
\hline I would participate in a "bring a friend" program organized by this OTA. & $3.89(1.71)$ \\
\hline In general, I participate in the activities organized by this OTA in which I can win a reward. & $3.88(1.63)$ \\
\hline \multicolumn{2}{|l|}{ Customers' interactions $(\alpha=0.90 ; \mathrm{CR}=0.94 ; \mathrm{AVE}=0.83)$} \\
\hline $\begin{array}{l}\text { I assess and share with other users my opinions and experiences about the products and services } \\
\text { of this OTA on the company website. }\end{array}$ & $4.21(1.60)$ \\
\hline $\begin{array}{l}\text { I write comments in the blog and/or in the profile of this OTA in social networks (e.g., Facebook, } \\
\text { Twitter, etc.). }\end{array}$ & $3.64(1.70)$ \\
\hline $\begin{array}{l}\text { I write comments in the forums on this OTA. }\end{array}$ & $3.59(1.74)$ \\
\hline \multicolumn{2}{|l|}{ Co-creation $(\alpha=0.93 ; \mathrm{CR}=0.95 ; \mathrm{AVE}=0.75$; Bettencourt et al. 1997) } \\
\hline I let this OTA know of ways that they can better serve my needs. & $4.53(1.55)$ \\
\hline I make constructive suggestions to this OTA about how to improve its service. & $4.27(1.63)$ \\
\hline If I have a useful idea of how to improve service, I give it to someone at this OTA. & $4.17(1.65)$ \\
\hline When I experience a problem at this store, I let someone know so they can improve the service. & $4.68(1.52)$ \\
\hline If I notice a problem, I inform an employee of this OTA even if it does affect me. & $4.21(1.55)$ \\
\hline If this OTA gives me good service, I let them know. & $4.70(1.59)$ \\
\hline \multicolumn{2}{|l|}{ Relationship quality $(\alpha=0.91 ; \mathrm{CR}=0.93 ; \mathrm{AVE}=0.70 ; \mathrm{Ng}$, David, and Dagger 2011) } \\
\hline Overall, I am satisfied with this OTA. & $5.32(1.03)$ \\
\hline I am very happy with this OTA. & $5.27(1.06)$ \\
\hline This OTA can be trusted. & $5.47(1.12)$ \\
\hline This OTA is trustworthy. & $5.47(1.13)$ \\
\hline I am very committed to this OTA. & $4.36(1.40)$ \\
\hline I believe that I will continue to use this OTA frequently in the future. & $5.28(1.17)$ \\
\hline \multicolumn{2}{|l|}{ Rewards $(\alpha=0.97 ; \mathrm{CR}=0.97 ; \mathrm{AVE}=0.91)$} \\
\hline I find the sweepstakes organized by this OTA attractive. & $4.44(1.48)$ \\
\hline I find the contests organized by this OTA attractive. & $4.42(1.46)$ \\
\hline I find the activities organized by this OTA in which I can win a prize attractive. & $4.53(1.46)$ \\
\hline In general, I find the prizes and presents by this OTA attractive. & $4.62(1.48)$ \\
\hline \multicolumn{2}{|l|}{ Self-enhancement $(\alpha=0.91 ; \mathrm{CR}=0.94 ; \mathrm{AVE}=0.80$; Henning-Thurau et al. 2004) } \\
\hline I regularly visit this OTA (its website, social networks, etc.), because & \\
\hline I like telling others that I have made a good choice. & $4.44(1.40)$ \\
\hline I like when I can tell others about my buying success. & $4.67(1.38)$ \\
\hline I like telling others about a good experience. & $4.80(1.38)$ \\
\hline My contributions show others that I am a clever customer. & $4.30(1.53)$ \\
\hline \multirow{2}{*}{\multicolumn{2}{|c|}{$\begin{array}{l}\text { Learning }(\alpha=0.86 ; \mathrm{CR}=0.94 ; \mathrm{AVE}=0.88 ; \text { Nambisan and Baron } 2007 \text { ) } \\
\text { I regularly visit this OTA (its website, social networks, etc.), because }\end{array}$}} \\
\hline & \\
\hline I enhance my knowledge about the service, related services, and their uses. & $4.62(1.27)$ \\
\hline I obtain solutions to specific service use related problems. & $4.46(1.28)$ \\
\hline \multicolumn{2}{|l|}{ Social integration $(\alpha=0.95 ; \mathrm{CR}=0.97 ; \mathrm{AVE}=0.91 ;$ Nambisan and Baron 2007) } \\
\hline I regularly visit this OTA (its website, social networks, etc.), because & \\
\hline I expand my personal/social network. & $4.30(1.37)$ \\
\hline I enhance the strength of my affiliation with the customer community. & $3.92(1.47)$ \\
\hline I enhance my sense of belongingness to this community. & $3.95(1.52)$ \\
\hline \multicolumn{2}{|l|}{ Company identification $(\alpha=\mathrm{NA} ; \mathrm{CR}=\mathrm{NA} ; \mathrm{AVE}=\mathrm{NA}$; Bergami and Bagozzi 2000) } \\
\hline I identify with this OTA & $4.55(1.26)$ \\
\hline
\end{tabular}


Our data was collected using a web-based survey. Online surveys are increasingly used in market research and produce results comparable with other data collection methods, particularly if respondents are familiar with online contexts (Deutskens et al., 2006), which they are in our research. The survey was conducted by a professional marketing research firm. Our respondents were asked about the CEB considered in this study and their antecedents in terms of the online travel agency they use the most. The respondents who participated in the study were randomly selected using stratified sampling $(n=466)$. Their demographics are representative of Internet users in Spain who browse the Internet for travel and accommodation purposes. Of the respondents, $47.42 \%$ are women and $52.58 \%$ are men (48.06\% and 51.94\% in the population of these Internet users in Spain). Regarding their age, $15.24 \%$ of the respondents are 16-44 years of age (15.74\% in the population), $29.18 \%$ are $25-34$ years $(29.34 \%), 27.04 \%$ are $35-44$ years $(26.43 \%), 17.60 \%$ are $45-55$ years $(17.74 \%)$, and $10.94 \%$ are older than 55 years $(10.66 \%)$.

\subsection{Measures}

Most of our measures were based on prior research and adapted to the context of online travel agencies. The original measures were loyalty program participation and customer interactions, and rewards. These measures were consistent with standard practices of the two online travel agencies we considered for this study. CEB has been proposed as a type II reflective-formative second-order construct (Ringle et al., 2012). That is, CEB is considered as a second-order formative construct whose items are reflective first-order constructs. These items are WOM, loyalty program participation, customer interactions, and co-creation. The antecedents of CEB are first-order reflective constructs. All of the first-order constructs of this research were assessed using seven-point Likert-type scales. Table 1 lists all the measures.

\section{Results}

\subsection{Analysis procedure}

We employed partial least squares (PLS) to estimate our model with SmartPLS 2.0 (Ringle et al., 2005). PLS is chosen for this study for three reasons. First, in contrast to covariance-based structural equation models, PLS can handle the non-multivariate normal data we collected. Second, we focused on common antecedents of CEB, and we deliberately omitted others that affect only of one of these behaviors. PLS is less sensitive than other structural equation models to variables omission (Chin, 2010). Third, as we explained before, our model includes CEB as a type II second-order construct. PLS is the most appropriate for the estimation of this type of construct.

When a type II second-order construct is not endogenous, the model can be estimated using a repeated indicator approach, in which the second-order construct is created as a latent variable that include all the manifest variables of the underlying first-order constructs (Wetzels et al., 2009). In our research, CEB would be measured through the manifest variables of WOM, loyalty program participation, customer interactions, and co-creation. On the other hand, when the type II second-order construct is endogenous, the model needs to be estimated using a two-stage approach (Ringle et al., 2012). This is the case of our research. In this two-stage approach, the model is first estimated using the repeated indicators approach in order to obtain the latent variable scores of the first-order variables. In this stage the variance of the second-order construct is explained by its lower order components ( $\mathrm{R}^{2}$ tends to 1$)$ and, consequently, the path relationships towards the second-order construct tend to be zero and nonsignificant. In the second stage, these latent variable scores are employed as manifest 
variables for the second-order construct and the model is re-estimated. This allows the predecessors of the second-order construct to explain part of its variance.

For this research, therefore, we have applied the two-stage approach. We have performed its first stage by including the manifest variables of the first-order constructs in two ways -reflective and formative - as previous research does not provide precise guidelines in this regard (Becker et al., 2012). Subsequently we have re-estimated the model using the latent scores we have obtained in the previous stage. The results are consistent in terms of the inner and the outer models. For the sake of brevity, we present only the results of the reflective estimation. Particularly, we present our results as follows: First, we describe the results of our measurement model (first stage of the two-stage approach for first-order constructs and second stage for the second-order formative construct). Subsequently, we discuss the estimation results of our structural model with regard to our hypotheses by using the results from the second phase of the two-stage approach.

\subsection{Measurement model}

We examined the reliability, convergent validity, and discriminant validity of the indicators of our first-order constructs, i.e. antecedents, WOM, participation in loyalty programs, customer interactions and co-creation (Table 1). The Cronbach's alpha values of these latent variables range between 0.86 and 0.97 , which is above the cutoff value of 0.7 proposed by Nunally (1978). Similarly, composite reliability varies between 0.93 and 0.97 . The loadings of the items used in our study are all above 0.7 , indicating indicator reliability. Regarding the convergent validity, the variance extracted (AVE) from the variables ranges from 0.70 to 0.91 , which is above the value of 0.5 suggested by Fornell and Larcker (1981). Finally, we examined the discriminant validity of the variables in our model in two ways.

Table 2. Discriminant Validity Analysis

\begin{tabular}{lcccccccccc}
\hline Constructs & $(1)$ & $(2)$ & $(3)$ & $(4)$ & $(5)$ & (6) & (7) & (8) & (9) & (10) \\
\hline WOM (1) & $\mathbf{0 . 9 0}$ & & & & & & & & & \\
Participation in loyalty programs (2) & 0.49 & $\mathbf{0 . 9 1}$ & & & & & & & & \\
Customers' interactions (3) & 0.57 & 0.71 & $\mathbf{0 . 9 1}$ & & & & & & & \\
Co-creation (4) & 0.63 & 0.56 & 0.72 & $\mathbf{0 . 8 6}$ & & & & & & \\
Relationship quality (5) & 0.59 & 0.27 & 0.36 & 0.43 & $\mathbf{0 . 8 4}$ & & & & & \\
Loyalty programs (6) & 0.57 & 0.66 & 0.56 & 0.56 & 0.46 & $\mathbf{0 . 9 5}$ & & & & \\
Self-enhancement (7) & 0.68 & 0.51 & 0.61 & 0.65 & 0.50 & 0.55 & $\mathbf{0 . 8 9}$ & & & \\
Learning (8) & 0.63 & 0.48 & 0.57 & 0.62 & 0.59 & 0.56 & 0.70 & $\mathbf{0 . 9 4}$ & & \\
Social integration (9) & 0.54 & 0.58 & 0.64 & 0.60 & 0.48 & 0.54 & 0.64 & 0.68 & $\mathbf{0 . 9 5}$ & \\
Company identification (10) & 0.64 & 0.43 & 0.53 & 0.55 & 0.67 & 0.55 & 0.58 & 0.68 & 0.62 & $\mathbf{1 . 0 0}$ \\
\hline
\end{tabular}

First, we employed the Fornell and Larcker (1981) criterion by which a latent variable has to share more variance with its indicators that with other variables; statistically, the square root of the AVE of a latent variable has to be higher than its correlations with other variables (Table 2). Secondly, the loadings of the indicators of a variable all have to be higher on its assigned latent variable than on others. In both cases, our results support the discriminant validity of our variables. After evaluating the measurement of the first-order constructs of our model we have included the latent scores of WOM, participation in loyalty programs, customer interactions and co-creation as manifest indicators of CEB and re-estimated the model. We have evaluated the measurement model of CEB by analyzing the significance of the manifest variables. They are all positive and significant at least at 95\% level (we have evaluated significance by using a nonparametric bootstrapping procedure with 5000 subsamples, no sign change). Additionally we have checked the lack of multicollinearity by 
employing variance inflation factors. These range from 1.76 to 1.93 , thus indicating that our measurement model for CEB does not suffer from multicollinearity.

\subsection{Hypotheses testing}

The fit of our model is assessed using the $\mathrm{R}^{2}$ of our endogenous variable. We have obtained a 0.73. This fit can be classified as substantial (Chin, 1988). In order to evaluate the significance of the path coefficients in the model, we used a nonparametric bootstrapping procedure with 5000 subsamples (no sign change). The path estimates are shown in Table 3. In $\mathrm{H} 1$, we analyzed the impact of relationship quality on CEB. Our results indicate that relationship quality does not influence CEB. Thus, we have not found support for H1. Higher levels of relationship quality do not lead to a more intense CEB. H2 postulated that the impact of rewards on CEB is positive. Our results support this relationship, corroborating that CEB can be enhanced by the rewards offered by companies through loyalty programs. H3 aimed to capture the influence of self-enhancement on CEB. We found that self-enhancement has a positive impact on CEB, thus supporting H3. We tested the impact of learning on CEB in H4. We found that this path is significant. Thus, our results support H4, learning directly and positively affects CEB. In H5, we postulated that social integration has a positive impact on CEB. Our results support such effect. Customers who enjoy interacting with peers are more prone to CEB. We proposed in H6 that company identification positively influences CEB. We found support for H6. Table 3 summarizes hypothesis-testing results.

We explored changes in $\mathrm{R}^{2}$ in order to investigate the impact of each antecedent on CEB, by computing effects size (Table 3 ). In particular, we ran our model six times, excluding one of the antecedents in each run. Subsequently, we calculated effect size as $\left(\mathrm{R}^{2}\right.$ included $\mathrm{R}^{2}$ excluded $) /\left(1-\mathrm{R}^{2}\right.$ included $)$ and interpreted the results in accordance with Cohen's (1998) categorization (>.02 weak, $>.15$ moderate, $>.35$ strong). Loyalty program has a moderate effect on CEB (.16), followed by self-enhancement (0.14), social integration (0.04), company identification (0.03). Learning and relationship quality has effect size lower than 0.02 .

Table 3: Estimates for the Structural Model

\begin{tabular}{lccccc}
\hline Antecedents & Estimates & t-value & $\mathrm{p}$ & Hypotheses & Effects size \\
\hline Relationship quality & 0.05 & 0.95 & n.s. & H1 rejected & n.s. \\
Rewards & 0.33 & 7.23 & $* * *$ & H2 supported & 0.03 \\
Self enhancement & 0.32 & 6.63 & $* * *$ & H3 supported & 0.16 \\
Learning & 0.11 & 2.35 & $* *$ & H4 supported & 0.15 \\
Social Integration & 0.21 & 3.96 & $* * *$ & H5 supported & 0.01 \\
Company identification & 0.14 & 3.62 & $* * *$ & H6 supported & 0.04 \\
\hline
\end{tabular}

$* * * p<0.01, * * p<0.05$, n.s. $=$ nonsignificant

\section{Discussion}

This research proposes a formative construct of CEB and analyzes the impact of its antecedents. Our findings improve our understanding of CEB drivers. The model incorporates $\mathrm{CEB}$ as a composite measure (WOM, loyalty program participation, customer interaction, and co-creation) and six antecedents based on the previous literature (relationship quality, rewards, self-enhancement, learning, social integration and company identification). Thus, while prior research offers a rather fragmented view of CEB, our study draws a more holistic picture of CEB in terms of construct and its antecedents. Our findings clearly suggest that the simultaneous impact occurs for five out of six antecedents, and that these antecedents explain more than the $50 \%$ of the variance of CEB. The CEB's antecedents can be classified in two categories: intrinsic and extrinsic. Intrinsic antecedents are expected benefits from CEB 
(rewards, learning, self-enhancement, and social integration) and can therefore be reinforced by directly managing $\mathrm{CEB}$. In contrast, extrinsic antecedents are not necessarily linked to CEB (relationship quality and company identification) and can therefore be reinforced by other means rather than CEB. This intrinsic-extrinsic antecedents dyad has not been introduced in the literature, thus offers an incremental value to our knowledge on CEB. What is intrinsic or extrinsic is a question directly related to firms' customer relationship management. In this light, our intrinsic-extrinsic dyad seems much related to tactical-strategic dyad in marketing. That is, intrinsic CEB antecedents are tactical in nature, which are essentially enhanced by pragmatic marketing tools, such as sales promotion. In contrast, extrinsic CEB antecedents are strategic in nature, which are directly related to firms' longterm goals and objectives. Future research should seek more theoretical foundations for this typology. In general, everything else being equal, an increase in any antecedent but relationship quality could strengthen CEB. Depending on the type of antecedents, we can predict to what extent we can enhance the value obtained from customers. A logical extension of this research would be to explore the potential interactions between the antecedents than influence CEB. Such research would result in a more holistic view of CEB.

Managerially, our findings offer several implications to practitioners. First, CEB must be managed as a whole and not independently. Marketers and customer relationship managers should not only directly enhance CEB through its intrinsic antecedents, but also keep constant eyes on its extrinsic antecedents. As we discussed before, both relationship quality and company identification require a long-term view of CEB, as they need to be built consistently and continuously over long period of time. Marketers and customer relationship managers should consider these issues in light of the firms' long-term strategic planning.

Several limitations should be recognized to make our findings more objective. First and foremost, our selection of the CEB antecedents was somewhat arbitrary, due to a lack of an overarching theory. Some may argue that our study could have included other antecedents to provide a more complete picture of CEB. Second, this study used online travel agencies as a research context. Therefore, our findings may be unique and specific to this particular industry. Any generalization of our findings should therefore be treated with caution. Third, our study did not include negative valence of CEB, such as negative WOM. Finally, our model estimation was based on cross-sectional data. Some of the antecedents of CEB can also be a consequence of the CEB (Brodie et al. 2011). Employing longitudinal data would solve this limitation. Together with the incorporation of other antecedents and CEB, this could constitute a fruitful area for further research.

\section{References}

Anderson, E.W. (1998), "Customer Satisfaction and Word of Mouth," Journal of Service Research, 1(1), 5-17.

Becker, J.M., Klein, K., and Wetzels, M. (2012), "Hierarchical Latent Variable Models in PLS-SEM: Guidelines for Using Reflective-Formative Type Models”, Long Range Planning, 45 (5-6), 359-394.

Bergami, M., and Bagozzi, R.P. (2000), "Self-Categorization, Affective Commitment and Group Self-Esteem as Distinct Aspects of Social Identity in the Organization," British Journal of Social Psychology, 39(4), 555-577.

Bettencourt, L.A. (1997), "Customer Voluntary Performance: Customers as Partners in Service Delivery," Journal of Retailing, 73(3), 383-406.

Bhattacharya, C.B., and Sen, S. (2003), "Consumer-Company Identification: A Framework for Understanding Consumers' Relationships with Companies," Journal of Marketing, 67(2), 76-88. 
Bolton, R.N. (2011), "Customer Engagement: Opportunities and Challenges for Organizations," Journal of Service Research, 14(3), 272-274.

Brodie, R.J., Hollebeek, L.D., Juric, B., and Ilic, A. (2011), "Customer Engagement: Conceptual Domain, Fundamental Propositions, and Implications for Research," Journal of Service Research, 14(3), 252-271.

Brown, T.J., Barry, T.E., Dacin, P.A., and Gunst, R.F. (2005), "Spreading the Word: Investigating Antecedents of Consumers' Positive Word-of-Mouth Intentions and Behaviors in a Retailing Context," Journal of the Academy of Marketing Science, 33(2), 123-138.

Chin, W.W. (1998), “The Partial Least Squares for Structural Equation Modeling," in Modern Methods for Business Research, George A. Marcoulides, ed. Mahwah, NJ: Lawrence Erlbaum.

Chin, W.W. (2010), "How To Write Up And Report PLS Analyses," in Handbook of Partial Least Squares, V. Esposito Vinzi, W.W. Chin, J. Hensler, and H.H. Wang, eds. Heidelberg: Springer.

Chu, S.C., and Kim, Y. (2011), "Determinants of Consumer Engagement in Electronic Wordof-Mouth (Ewom) in Social Networking Sites," International Journal of Advertising, $30(1), 47-75$.

Cohen, J. (1988), Statistical Power Analysis for the Behavioral Sciences, $2^{\text {nd }}$ ed. Hillsdale, NJ: Lawrence Erlbaum Associates.

Deutskens, E., de Ruyter, K., and Wetzels, M. (2006), "An Assessment of Equivalence between Online and Mail Surveys in Service Research," Journal of Service Research, $8(4), 346-355$.

Dowling, G.R., and Uncles, M. (1997), "Do customer loyalty programs really work?" Sloan Management Review, 38(4), 71-82.

Dutton, J.E., Dukerich, J.M., and Harquail, C.V. (1994), “Organizational Images and Member Identification," Administrative Science Quarterly, 39(2), 239-263.

Fornell, C., and Larcker, D.F. (1981), "Evaluating Structural Equation Models with Unobservable Variables and Measurement Error," Journal of Marketing Research, 18(1), 39-50.

Franke, N., and Shah, S. (2003), "How Communities Support Innovative Activities: An Exploration of Assistance and Sharing among End-Users," Research Policy, 32, 157 178.

Godes, D., and Mayzlin, D. (2004), "Using Online Conversations to Study Word-of-Mouth Communication," Marketing Science, 23(4), 545-560.

Grönroos, C. (2012), "Conceptualising Value Co-Creation: A Journey to the 1970s and Back to the Future," Journal of Marketing Management, 28(13-14), 1520-1534.

Hennig-Thurau, T., and Klee, A. (1997), "The Impact of Customer Satisfaction and Relationship Quality on Customer Retention: A Critical Reassessment and Model Development," Psychology \& Marketing, 14(8), 737-764.

Hennig-Thurau, T., Gwinner, K.P., and Gremler, D.W. (2002), "Understanding Relationship Marketing Outcomes: An Integration of Relational Benefits and Relationship Quality," Journal of Service Research, 4(3), 230-247.

Hennig-Thurau, T., Gwinner, K.P., Walsh, G., and Gremler, D.D. (2004), "Electronic Wordof-Mouth Via Consumer-Opinion Platforms: What Motivates Consumers to Articulate Themselves on the Internet?" Journal of Interactive Marketing, 18(1), 38-52.

Kim, E.E.K., Mattila, A.S., and Baloglu, S. (2011), "Effects of Gender and Expertise on Consumers' Motivation to Read Online Hotel Reviews," Cornell Hospitality Quarterly, 52(4), 399-406. 
Kumar, V., Aksoy, L., Donkers, B., Venkatesan, R., Wiesel, T., and Tillmanns, S. (2010), "Undervalued or Overvalued Customers: Capturing Total Customer Engagement Value," Journal of Service Research, 13(3), 297-310.

Libai, B., Bolton, R., Bügel, M.X., de Ruyter, K., Götz, O., Risselada, H., and Stephen, A.T. (2010), "Customer-to-Customer Interactions: Broadening the Scope of Word of Mouth Research," Journal of Service Research, 13(3), 267-282.

Macintosh, G. (2007), "Customer Orientation, Relationship Quality, and Relational Benefits to the Firm," Journal of Services Marketing, 21(3), 150-159.

Morgan, R.M., and Hunt, S.D. (1994), "The Commitment-Trust Theory of Relationship Marketing," Journal of Marketing, 58(3), 20-38.

Nambisan, S., and Baron, R.A. (2010), "Different Roles, Different Strokes: Organizing Virtual Customer Environments to Promote Two Types of Customer Contributions," Organization Science, 21(2), 554-572.

Nambisan, S., and Baron, R.A. (2007), "Interactions in Virtual Customer Environments: Implications for Product Support and Customer Relationship Management," Journal of Interactive Marketing, 21(2), 42-62.

Ng, S., David, M.E., and Dagger, T.S. (2011), "Generating Positive Word-of-Mouth in the Service Experience," Managing Service Quality, 21(2), 133-151.

Nunnally, J. C. (1978), Psychometric Theory, $2^{\text {nd }}$ ed. New York: McGraw-Hill.

Oyedele, A., and Simpson, P.M. (2011), "Understanding Motives of Consumers Who Help," Journal of Strategic Marketing, 19(7), 575-589.

Ringle, C.M., Sarstedt, M., and Straub, D.W. (2012), "Editor's comments: a critical look at the use of PLS-SEM in MIS quarterly", MIS Quarterly, 36 (1), iii-xiv.

Ringle, C.M., Sende, S., and Will, A. (2005): Smart PLS 2.0 (M3) Beta, Hamburg 2005, http://www.smartpls.de.

Ryu, G., and Feick, L. (2007), “A Penny for Your Thoughts: Referral Reward Programs and Referral Likelihood," Journal of Marketing, 71(1), 84-94.

Shabbir, H., Palihawadana, D., and Thwaites, D. (2007), "Determining the Antecedents and Consequences of Donor-Perceived Relationship quality-a Dimensional Qualitative Research Approach," Psychology \& Marketing, 24(3), 271-293.

Sundaram, D.S., Mitra, K., and Webster, C. (1998), "Word-of-Mouth Communications: A Motivational Analysis," Advances in Consumer Research, 25(1), 527-531.

van Doorn, J., Lemon, K.N., Mittal, V., Nass, S., Pick, D., Pirner, P., and Verhoef, P.C. (2010), "Customer Engagement Behavior: Theoretical Foundations and Research Directions," Journal of Service Research, 13(3), 253-266.

Verhoef, P.C., Reinartz, W.J., and Krafft, M. (2010), "Customer Engagement as a New Perspective in Customer Management," Journal of Service Research, 13(3), 247-252.

Wasko, M.M., and Faraj, S. (2000), "It is What One Does: Why People Participate and Help Others in Electronic Communities of Practice, Journal of Strategic Information Systems, 9, 155-173.

Wetzels, M., Odekerken-Schröder, G., and van Oppen, C. (2009), "Using PLS path modeling for assessing hierarchical construct models: guidelines and empirical illustration," MIS Quarterly, 33 (1), 177-195.

Wirtz, J., Orsingher, C., Chew, P., and Tambyah, S.K. (2013), "The Role of Metaperception on the Effectiveness of Referral Reward Programs," Journal of Service Research, 16(1), 82-98.

Xu, B., Li, D., and Shao, B. (2012), "Knowledge Sharing in Virtual Communities: A Study of Citizenship Behavior and its Social-Relational Antecedents," International Journal of Human-Computer Interaction, 28(5), 347-359. 